\title{
Research into the Influence of Outward Bound on University Students' Level of Mental Health
}

\author{
Dazhi Dong \\ Hohai University \\ Changzhou, China, 213022
}

\begin{abstract}
Mental health is the basic guarantee for university students to study, communicate, live their lives and develop. In order to improve university students' quality in the round, develop qualified talents adapted to modern society, reinforce the education on university students' mental health, symptom checklist and sport rating scale are used to discuss the function of mental outward bound on university students' mental health to provide some references and basis for reform on the education courses of universities and colleges from the angle of improving university students' mental health level by studying the mental health of university students.
\end{abstract}

Keywords-University students; Mental health; Outward bound

\section{OBJECT AND METHOD}

\section{A. Object}

The stratified cluster sampling method is used to sample 30 Year-2009 university students and 60 Year-2010 university students from Jiangsu Industrial College in a stratified way at random to be tested in the outward bound teaching experiment. The average age of the 90 students is (20.52 \pm 1.26$)$. Year-2009 and Year-2010 students from other three sport classes are selected at random as the control group.

\section{B. Purpose}

According to the test results, it is verified that mental outward bound as an effective method may promote the improvement of university students' mental health level.

\section{Research method}

1) Based on literature Refer to such books as Mental Health, Social Psychology of Sports, Health Education, Measurement of Mental Health, hundreds of papers from sport journals.

2) Symptom checklist (SCL-90) is used for measurement; SCL-90 is a general tool for measuring the mental health. In the checklist, there are 90 items in total including nine factors such as somatization, force, interpersonal sensitivity, depression, anxiety, hostility, terror, paranoid, trauma and so on. The Sport Rating Scale (modified by Liang Deqing in

Topic on Funding the Humanities and Social Sciences Research of Jiangsu Polytechnic University:(JW200907)
1994); the self-assessment questionnaires of social adaptability prepared by $\mathrm{Fu}$ Jen Applied Mental Development Center of Beijing Normal University is used to measure university students' social adaptability.

3) The data measured by using the mathematical statistics are processed with the soft SPSS13.0, and t-tested.

4) The students are grouped for the teaching test before the teaching test by using the experimental method, including the mental outward bound teaching test group; and the volleyball class and the badminton class as the control group.

5) In the research using the expert interview method, we have listened to experts' ideas on the experiment design and test methods for many times to ensure that the research goes smoothly.

\section{Design OF The TEACHING Process}

Design of testing schemes.

The students are grouped for the teaching test before the teaching test by using the experimental method, including the mental outward bound teaching test group; and the volleyball class and the badminton class as the control group.

Control over the testing conditions Various testing conditions are controlled so that the external factors affecting the results of the experiment group and the control group are minimized; the sport rating scale is used to measure both groups to ensure the testing results reliable and comparable; the students are strictly grouped into the mental outward bound teaching experiment group, and the control group; the symptom checklist (SCL-90) is used for measuring and assessing the mental health level, and the measurement and assessment is in the charge of an expert from the mental teaching and research office to learn about the mental health of the students before and after the sports. The experimenters are two teachers and use uniform guidance to measure the students' mental health at the same time and collect the data.

During testing, classes are given strictly according to the outward bound syllabus and teaching plans for 18 weeks per semester including 2 indoor theoretical classes, 16 outdoor outward bound classes. The total number of periods is 36 per semester. See Table (1) and Table (2) for the items assessed and standards. 
Standards for assessing the special outward bound items: (1) Teamwork (10\%); (2) Self-challenge ability (10\%); (3) Ability to communicate $(10 \%)$; (3) Abilities to solve problems $(10 \%)$ See the attached syllabus for details.

Testing time and frequency for doing exercises per week The test starts from September, 2008 to January, 2009; in the test, classes are had for 18 weeks, 36 periods in total, strictly according to the syllabus and teaching plans. The objects have classes once every week, 95 minutes every time, including 25-20 minutes for sharing and reviewing exercises.

Control over testing conditions Various testing conditions are controlled so that the external factors affecting the results of the experiment group and the control group are minimized; the sport rating scale is used to measure both groups to ensure the testing results reliable and comparable; the students are strictly grouped in the teaching test.

\section{RESULTS AND ANALYSIS}

The sport rating scale (PARS-3) modified by Liang Deqing is used to assessing the amount of exercises from the angle of strength, time and frequency of doing exercises, and the scale of the amount of exercises is of no significant difference. It can be seen according to Table 3 that the amount of exercises of the experiment group and the control group is of no significant difference.

TABle 1 Items Assessed And Their Proportions In THe Outward Bound

\begin{tabular}{|c|c|c|c|}
\hline Items assessed & $\begin{array}{c}\text { Special outward bound } \\
\text { items }\end{array}$ & Physique & Theories \\
\hline Proportion & 40 & 30 & 10 \\
\hline
\end{tabular}

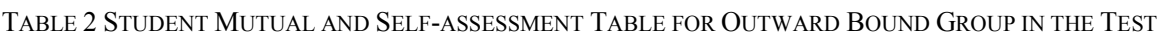

\begin{tabular}{|c|c|c|c|c|}
\hline Items assessed & Teamwork & Self-challenge ability & Ability to communicate & Ability to solve problems \\
\hline \multicolumn{5}{|c|}{$\begin{array}{l}\text { (Self-assessment) } \\
\text { Mutual assessment }\end{array}$} \\
\hline
\end{tabular}

TABLE 3 COMPARISON OF THE AMOUNT OF EXERCISES BETWEEN THE EXPERIMENT GROUP AND CONTROL GROUP

\begin{tabular}{|c|c|c|c|}
\hline Group & N & $\mathbf{X} \pm \mathbf{S}$ & $\mathbf{P}$ \\
\hline Experiment group & 90 & $56.12 \pm 13.26$ & 13.29 \\
\hline Control group & 90 & $55.61 \pm 12.43$ & 14.22 \\
\hline
\end{tabular}

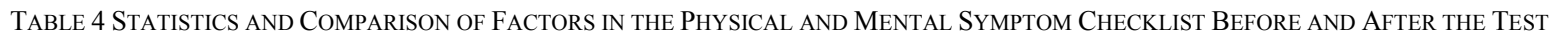

\begin{tabular}{|c|c|c|c|c|}
\hline \multirow{3}{*}{ Factors } & \multicolumn{2}{|c|}{ The first test } & \multicolumn{2}{|c|}{ The second test } \\
\hline & Experiment group & Control group & Experiment group & Control group \\
\hline & $(M \pm S D)$ & $(M \pm S D)$ & $(M \pm S D)$ & $(M \pm S D)$ \\
\hline Somatization & $1.24 \pm 0.41$ & $1.23 \pm 0.38$ & $1.02 \pm 0.36$ & $1.07 \pm 0.37 *$ \\
\hline Force & $1.62 \pm 0.42$ & $1.58 \pm 0.47$ & $1.56 \pm 0.44$ & $1.57 \pm 0.46$ \\
\hline Somatization & $1.24 \pm 0.41$ & $1.23 \pm 0.38$ & $1.02 \pm 0.36$ & $1.07 \pm 0.37 *$ \\
\hline Force & $1.62 \pm 0.42$ & $1.58 \pm 0.47$ & $1.56 \pm 0.44$ & $1.57 \pm 0.46$ \\
\hline Interpersonal sensitivity & $1.47 \pm 0.53$ & $1.46 \pm 0.62$ & $1.28 \pm 0.55$ & $1.44 \pm 0.51 * * \# \#$ \\
\hline Depression & $1.62 \pm 0.61$ & $1.60 \pm 0.57$ & $1.36 \pm 0.61$ & $1.54 \pm 0.53 \quad * * \quad \#$ \\
\hline Anxiety & $1.37 \pm 0.41$ & $1.38 \pm 0.53$ & $1.18 \pm 0.42$ & $1.32 \pm 0.37 * \quad \# \#$ \\
\hline Hostility & $1.44 \pm 0.49$ & $1.46 \pm 0.53$ & $1.31 \pm 0.51$ & $1.44 \pm 0.51 \quad * \quad \#$ \\
\hline Terror & $1.22 \pm 0.37$ & $1.22 \pm 0.42$ & $1.18 \pm 0.42$ & $1.19 \pm 0.27 \quad * \quad \#$ \\
\hline Paranoid & $1.41 \pm 0.55$ & $1.42 \pm 0.53$ & $1.13 \pm 0.22$ & $1.38 \pm 0.53 \quad * * \quad \# \quad \#$ \\
\hline Trauma & $1.27 \pm 0.42$ & $1.28 \pm 0.43$ & $1.27 \pm 0.42$ & $1.27 \pm 0.37$ \\
\hline Others & $1.58 \pm 0.37$ & $1.57 \pm 0.59$ & $1.37 \pm 0.37$ & $1.48 \pm 0.55 \quad * \quad \#$ \\
\hline
\end{tabular}

TABLE 5 SCORE OF THE SELF-ASSESSMENT QuestionNAIRES ON SOCIAL ADAPTABILITY

\begin{tabular}{|c|c|c|c|c|}
\hline \multirow{3}{*}{ Item } & \multicolumn{2}{|c|}{ The first test } & \multicolumn{2}{|c|}{ The second test } \\
\hline & Testing & Control & Testing & Control \\
\hline & $(M \pm S D)$ & $(M \pm S D)$ & $(M \pm S D)$ & $(M \pm S D)$ \\
\hline \multirow[t]{2}{*}{ Score } & 75. $15 \pm$ & 74. $90 \pm$ & 77. $67 \pm$ & 75. $61 \pm$ \\
\hline & 8.79 & 8.81 & 9.15 & 8. $91 * \#$ \\
\hline
\end{tabular}

Note:* means $\mathrm{P}<0.05$ between the experiment group and the control group, \# means $\mathrm{P}<0.05$ between the first test and the second test 
1) The mental outward bound may effectively improve university students' mental health level

According to the Comparison Table (4), there is no significant difference between the ten factors by comparing the factors of the experiment group and the control group in the first test (see Table 4, the testing factors are expressed by M, and SD means standard difference, $P$ means significant difference). It means that the mental health of the experiment group and the control group when the test starts is of no difference. Upon completion of the mental outward bound, it is found that the force, interpersonal relationship, anxiety and paranoid of students between the experiment group and the control group are of highly significant difference $(\mathrm{P}<0.01)$; and the factors of hostility depression and terror are of significant difference $(\mathrm{P}<0.05)$; the outward bound is conducted in groups, and mutual reliance, understanding and coordination of the students are promoted through complicated and hard exercises. Under the lead of the trainers, the students share their experience, and fully feel the purposes of the items arranged in the outward bound by means of reflection, self-examination, comprehension and communication. While the team works together and shares their happiness from success, they can be open to each other, communicate with each other and appreciate each other. This is helpful for their work and study in the future so that they may face the life in the future in a more active attitude.

2) Mental outward bound may improve university students' abilities to communicate and establish wide social relationship

According to Table (5), the difference in the social adaptability of the students between the experiment group and the control group is not significant, which means that their social adaptability is of no difference. During the test upon completion of the experiment, it is found that the social adaptability of the students between the experiment group and the control group is of significant difference $(\mathrm{P}<0.05)$, which means that after the 18-week mental outward bound, the social adaptability of the university students from the experiment group is significantly different from that of the control group, which means that the mental outward bound is helpful for improving the social adaptability of university students.

\section{CONCLUSIONS AND SUGGESTIONS}

According to the experiment, the mental outward bound is helpful for improving the mental health of university students, and the difference in the force, interpersonal relationship, anxiety, paranoid is highly significant $(\mathrm{P}<0.01)$; the difference in hostility, depression and terror is significant $(\mathrm{P}<0.05)$.

The difference in the social adaptability between the experiment group and the control group is significant $(\mathrm{P}<0.05)$, which means that the social adaptability of the university students from the experiment group is significantly better than that of the control group. It means that the mental outward bound is helpful for improving university students' social adaptability.
Right amount of regular planned mental outward bound is helpful for improving the university students' mental health level; the flexibly organized training mode and experiential training objective make it feasible to improve the mental health level of university students; the following meets the requirements of the current health objectives: supplementing and extending the content and function of P.E. with the outward bound modes.

\section{REFERENCES}

[1] [1] Jian Bo. Outward Bound and Research into it in Chinese P.E. Teaching [J]. Journal of Jiangsu Polytechnic University 2007 (4)

[2] [2] Qi Guoying etc. Practical Statistics[M].Beijing: Beijing Sport University Press, 1995, 5.

[3] [3] Lin Guangyao. Analysis of the Relevance between the Sports and Mental Health [J].Sichuan Sport Science, 2003(3):15-16.

[4] [4] Jian Bo. About the Prospect for Outward Bound in Universities and Colleges[J]. Journal of Changzhou College of Information Technology, 2007, 6(3):46-48.88-91. 